\title{
Economic incentives and overfishing: a bioeconomic vulnerability index
}

\author{
William W. L. Cheung ${ }^{1, *}$, U. Rashid Sumaila ${ }^{2}$ \\ ${ }^{1}$ Changing Oceans Research Unit and ${ }^{2}$ Fisheries Economics Research Unit, University of British Columbia, 2202 Main Mall, \\ Vancouver, BC V6T 1Z4, Canada
}

\begin{abstract}
Bioeconomic theory predicts that the trade-offs between maximization of economic benefits and conservation of vulnerable marine species can be assessed using the ratio between the discount rate of fishers and the intrinsic rate of growth of the exploited populations. In this paper, we use this theory to identify areas of the global ocean where higher vulnerability of fishes to overfishing would be expected in the absence of management. We derive an index to evaluate the level of vulnerability by comparing discount rates and fishes' intrinsic population growth rates. Using published discount rates of countries that are reported to fish in the ocean and estimating the intrinsic population growth rate for major exploited fishes in the world, we calculate the vulnerability index for each $0.5^{\circ}$ latitude $\times 0.5^{\circ}$ longitude grid for each taxon and each fishing country. Our study shows that vulnerability is inherently high on the northeastern coast of Canada, the Pacific coast of Mexico, the Peruvian coast, in the South Pacific, on the southern and southeastern coast of Africa, and in the Antarctic region. It should be noted that this index does not account for the management regime currently in place in different areas, and thus mainly reflects the vulnerability resulting from the intrinsic life history characteristics of the fish species being targeted and the discount rates of the fishers exploiting them. Despite the uncertainties of this global-scale analysis, our study highlights the potential applications of large-scale spatial bioeconomics in identifying areas where fish stocks are more likely to be over-exploited when there is no effective fisheries management; this applies to many fisheries around the world today.
\end{abstract}

KEY WORDS: Vulnerability $\cdot$ Discount rate $\cdot$ Overfishing $\cdot$ Fisheries $\cdot$ Spatial bioeconomics Resale or republication not permitted without written consent of the publisher

\section{INTRODUCTION}

Fishing is an important economic, social and cultural activity for many communities in the world. Global marine fisheries currently directly and indirectly support 35 million jobs, generating a US\$ 35 billion fishing household income and US\$ 8 billion profits a year (Arnason et al. 2009). It provides employment in fishing, processing, and ancillary services, as well as through subsistence-based activities at the community level (Roy et al. 2009, Teh 2011, Teh et al. 2011). The economic impact of marine fisheries to the world economy was estimated at US\$ 220 to 235 billion in 2003 (Dyck \& Sumaila 2010). Nearly
1 billion people worldwide, or about $20 \%$ of the global population, rely on fish as a primary source of animal protein (FAO 2011). In many cases, fishing is undertaken for economic and/or social benefits such as revenues and livelihoods. But there is increasing focus on the impacts of over-exploitation on the conservation of marine species (Dulvy et al. 2003, Sadovy de Mitcheson et al. 2013), and the need to shift to ecosystem-based fisheries management (Pitcher \& Lam 2010). This means that fisheries management needs to achieve a more balanced portfolio of objectives.

The trade-offs between economic, social and conservation objectives become severe when the vulner- 
ability of exploited species to fishing and the incentive for overfishing are both high (Norse et al. 2012). In some extreme cases, fishing can drive species or stocks to local or near global extinction. For example, the Chinese bahaba Bahaba taipengensis in the South and East China Seas is inherently highly vulnerable to fishing because of its large body size and its tendency to form spawning aggregations. The species is considered to be Critically Endangered under the IUCN Red List of Endangered Species (www. redlist.org) primarily because it is highly targeted for its extremely valuable swimbladder as a traditional Chinese medicine (Sadovy \& Cheung 2003). Another example is the sea otter Enhydra lutris, which was hunted to near extinction along the North American coast for the fur trade (Doroff et al. 2003).

Life history and population dynamic theories predict that fish populations with a low reproductive rate are intrinsically more vulnerable to over-exploitation (Reynolds et al. 2005). This applies particularly to fishes that are large, slow-growing and late-maturing (Cheung et al. 2005). When subjected to similar fishing mortality rates, abundance of species with higher intrinsic vulnerability decrease faster than species with lower vulnerability, all else being equal (Cheung $\&$ Pitcher 2008). This systematic difference in sensitivity to fishing between fish species is partly the reason behind the increasing dominance of less vulnerable fish species in global fish catches (Cheung et al. 2007). However, such intrinsic vulnerability does not account for non-biological factors, such as intensity of fishing, which ultimately determine the level of fishing mortality and exploitation status of the populations.

Bioeconomic theory predicts that optimal fishing strategy is a function of the productivity of the exploited population (represented by the intrinsic rate of population increase), cost of fishing, price of the catch and the discount rate (Clark 1973). A common driver of overfishing is the open access nature of fisheries resources, under which each fishing unit seeks to maximize its own benefits from fishing, leading to over-exploitation of the resources. Moreover, the discount rate determines how much the flow of future costs and benefits is discounted to obtain the net present value. Thus, a high discount rate means that we value current benefits much more than those we can get (or lose) in the future (Sumaila 2004). Given this situation, it would be economically reasonable to increase the current exploitation of the resource, particularly if we will only incur the costs associated with such an action in the distant future (Sumaila \& Walters 2005). In fisheries, fishers are considered to have their own private discount rate that is based on the intuitive discounting they apply in their decision-making processes. However, the private discount rate of fishers has only been estimated in a few cases (e.g. Fehr \& Leibbrandt 2008, Teh et al. 2009). According to Clark (1973), when the discount rate is higher than the intrinsic rate of population increase, and all else being equal, the economically optimal fishing strategy would be to overfish the stocks. When the discount rate is much higher than the fishes' population growth rate, the theory predicts that it is economically rational to drive fish stocks to extinction (Clark 1973). Thus, we can expect that fish stocks in regions where discount rates are high while population growth rate is low would have a relatively higher vulnerability to overfishing.

A range of fisheries management strategies and tactics have been proposed to ensure the sustainability of fisheries (Walters \& Martell 2004). Some are 'command-and-control' type management measures that manage fisheries through limiting fishing or other activities, e.g. marine protected areas, while others are 'incentive'-based measures that use economic or other incentives to encourage sustainable fishing practices, e.g. transferrable quotas. However, these measures have their pros and cons. Understanding the key drivers and vulnerability to overfishing provides useful information for identifying suitable strategies and tactics to effectively manage the fisheries.

In the present study, we aimed to identify, on a global scale, the bioeconomic vulnerability of fishes to overfishing. We derived an index to evaluate the vulnerability resulting from both the intrinsic biological characteristics and the economic factors that may lead to overfishing. We collected published discount rates of countries that are reported to fish in the ocean. We estimated the intrinsic population growth rate for major exploited fish species in the world. Finally, using these estimates, we calculated the bioeconomic vulnerability index on a $0.5^{\circ}$ latitude $\times$ $0.5^{\circ}$ longitude grid for each taxon and fishing country from the 'Sea Around Us' project and identified areas where the potential for overfishing is most severe. We discuss the potential application of such an index to the evaluation of fisheries management options.

\section{METHODS}

\section{Deriving a bioeconomic vulnerability index}

Clark's theory (Clark 1973) shows that under certain conditions, when the discount rate of a private fishing unit $(\delta)$ is equal to or higher than the intrinsic 
population growth rate $(r)$ of a given fish species, the economically optimal fishing strategy would be to overexploit the targeted stock. The biological component of this model is based on a simple Schaefer model, in which

$$
F(X)=r \cdot X \cdot\left(1-\frac{X}{N}\right)
$$

where $X$ is the biomass and $N$ is the carrying capacity. Marginal change in population growth can be obtained by differentiating Eq. (1) with respect to $X$ :

Thus,

$$
F^{\prime}(X)=r \cdot\left(1-\frac{2 X}{N}\right)
$$

$$
\lim _{X \rightarrow 0} F^{\prime}(X)=r
$$

Assuming the fisheries manager's goal is to maximize the present value $(P V)$ of profits from the fishery, maximum $P V$ can be determined as follows:

$$
\max P V=\int_{0}^{\infty} \mathrm{e}^{-\delta}(p-c(X)) Y(t) \mathrm{d} t
$$

where $p$ is the unit price of a catch, $c(X)$ is the unit fishing cost, and $Y(t)$ is the catch in period $t$. Solving for Eq. (4) results in a biomass level, $X^{*}$, that gives the optimal discounted profit (Clark \& Munro 1975):

$$
F^{\prime}\left(X^{*}\right)-\frac{C^{\prime}\left(X^{*}\right) \cdot F\left(X^{*}\right)}{p-c\left(X^{*}\right)}=\delta
$$

Eq. (5) is a re-expression of the golden rule of capital theory for a renewable resource (Clark \& Munro 1975). The left-hand side of the equation is an expression of the 'own interest rate', which is essentially the instantaneous return on fish left in the ocean over a period of time. Specifically, the first term is an expression of the instantaneous marginal return on the fish, while the second term denotes the impact of investment in $X$ on the cost of fishing, $C(X)$, which is called the Marginal Stock Effect (MSE) (Clark \& Munro 1975). On the right-hand side, $\delta$ denotes the rate of return if a fish is caught and sold and the return is deposited in a bank account or invested elsewhere. Eq. (5) therefore states that the economically optimal stock level of a species is obtained when the 'own rate of interest' of the fish is exactly equal to the discount rate.

Now, as $X$ approaches $0, c(X)$ increases towards infinity as it becomes more and more difficult to find and catch fish when using the same technology, which implies

$$
\lim _{\left(X^{*}\right) \rightarrow 0} F^{\prime}\left(X^{*}\right)=\delta
$$

Combining Eqs. (1) and (5) and under the condition that the price per unit of fish $>c(0)$ (means that it would be worthwhile economically to catch every fish in the ocean), Clark's (1973) model shows that the necessary and sufficient conditions for overfishing and extinction as the economically rational fishing strategy under private resource ownership are $\delta>r$ and $\delta>2 \cdot r$, respectively. Moreover, the model implies that a private owner of the fishery is indifferent between 'fish in the bank' and 'fish in the ocean' when the discount rate equals the intrinsic growth rate of the population.

Based on these conditions, we derived an index $(\theta)$ to indicate the risk of over-exploitation according to the discount rate of the fisheries and the intrinsic population growth rate of the exploited fishes. This index is based on the assumption that $\delta>r$ is the sufficient and necessary condition to engage in overfishing, in which both $\delta$ and $r$ are expressed as annual rates. Thus, we defined this index simply as

$$
\theta=\left(1-\frac{\delta}{r}\right)
$$

The index has a negative value when the discount rate of the fisheries is higher than the intrinsic population growth rate of the exploited population, and vice versa. Based on Clark (1973), a negative or low index value indicates strong incentive for overexploitation. When $\delta \geq 2 \cdot r$, and therefore $\theta \leq-1$, the incentive for over-exploitation is so high that it may drive the species or stock to extinction.

\section{Global fisheries catch data}

We calculated the bioeconomic vulnerability index for all major exploited fish species in the world. These include 852 taxa of marine fishes that are reported at the species, genera and family levels by the United Nations Food and Agriculture Organization (FAO). In 2005, these taxa made up $84 \%$ of the global reported fish catch and were exploited by 178 countries. We extracted spatially-explicit catch data on a $0.5^{\circ}$ latitude $\times 0.5^{\circ}$ longitude grid for each taxon and each fishing country from the global catch database of the Sea Around Us project (see www.sea aroundus.org and Watson et al. [2004] for the detailed description of the database development).

The Sea Around Us catch data (www.seaaroundus. org) originates from a range of sources including the FAO fisheries database supplemented by regional datasets, e.g. from the International Council for the Exploration of the Sea (ICES) for Europe. Details of the spatial allocation of catches are documented in Watson et al. (2004). It is quality-checked and mapped to a grid of $\left(0.5^{\circ} \times 0.5^{\circ}\right)$ spatial cells using a rulebased approach based on original spatial informa- 
tion, the operation of fleets in the Exclusive Economic Zone of maritime countries (e.g. through documented access agreements) and the known habitatdriven distribution of the reported marine taxa. As a result, the location $\left(0.5^{\circ} \times 0.5^{\circ}\right.$ cell $)$ of each fishing nation's catch and the quantity caught were obtained for each year and for each reported taxon from this dataset.

\section{Discount rate by fishing countries}

The most readily available discount rate data is the official country-level discount rate. We collated such data for all fishing countries. For countries where officially published discount rates were not available, we assumed that the average Central Bank lending rates are proxy of their discount rates, obtained from statistics published by the International Monetary Fund. For countries that did not publish such data, we used the discount rates assumed by the World Bank, which were 7 and $10 \%$ for developed and developing countries, respectively (see Table S1 in the Supplement at www.int-res.com/articles/suppl/ m530p223_supp.pdf for the list of country-level discount rate used). It is worth noting that the World Bank's discount rates have been used in economic analysis of other global-scale fisheries, such as 'the Sunken Billions' by Arnason et al. (2009).

Because country-level discount rates may not reflect the discount rate of the private sector and may largely underestimate the discount rate of the fishing sector (Teh 2011, Teh et al. 2014), we attempted to estimate the private discount rate of the fishing sector. However, the availability of empirically estimated private discount rates is very limited. Available estimates for fisheries in Ghana (Akpalu 2008), Sabah (Malaysia) and Fiji (Teh 2011) range from 130 to $200 \%$ (Teh et al. 2014). We used these figures to determine the potential private discount rate for the fisheries in each country. Since the published discount rates are mainly for fishers in developing countries, we divided fishing countries into low, medium and high development according to their published Human Development Index. Based on our collated data, the average country-level discount rates of less developed countries were assumed to be 1.5 and 2 times higher than the discount rates of moderately and highly developed countries, respectively. Thus, we assumed that fishers in the moderately developed countries have a discount rate of $165 \%$ (median of the available private discount rate estimates for the fishing sector), while the highly and less developed countries were assigned discount rates of 110 and $220 \%$, respectively.

\section{Estimating intrinsic population growth rate (r)}

We estimated the intrinsic population growth rate (Table S2 in the Supplement) based on the EulerLotka method (McAllister et al. 2001). In this method, $r$ is approximated from the following equation:

$$
\sum_{a=0}^{A} \mathrm{e}^{-r \cdot a} \cdot l_{a} \cdot m_{a}=1
$$

where $a$ and $A$ are the age-class and longevity of the population, respectively; $l_{a}$ is the expected survivorship of females from age 0 to age $a_{i}$ and $m_{a}$ is the expected number of age- 0 female offspring per individual female or fecundity at age $a$.

We estimated the parameters in Eq. (8) using Eqs. (9-13) and then solved for $r$ iteratively, using a numerical minimization function (Solver in Microsoft Excel). We assumed a Beverton-Holt recruitment function and expressed it as a function of the steepness parameter $h$, defined as the recruitment when spawning biomass is $20 \%$ of the unfished level (Mangel et al. 2010). In general, $h$ scales between 0.2 to 1 (Mangel et al. 2010).

Thus,

and

$$
h \cdot R_{0}=\frac{0.2 B_{0}}{\alpha+0.2 \beta B_{0}}
$$

$$
\alpha=\frac{B_{0}}{R_{0}} \frac{1-h}{4 h}
$$

where $B_{0}$ is spawning biomass and and $R_{0}$ is recruitment of the unfished population, and thus, $B_{0} / R_{0}$ is the unfished equilibrium spawning biomass per recruit. $\alpha$ and $\beta$ are paramaters determining the shape of the Beverton-Holt stock recruitment function. $B_{0} / R_{0}$ is calculated from

$$
\frac{B_{0}}{R_{0}}=\sum_{a=0}^{A} W_{a} \cdot l_{a} \cdot \rho_{a}
$$

where $\rho_{a}$ is the proportion of sexually matured females at age $a$. We assumed a knife-edge maturity schedule in which all females become mature after the age of maturity; $W_{a}$ is the weight-at-age that is estimated from the von Bertalanffy growth function:

$$
W_{a}=W_{\infty} \cdot\left[1-e^{-k\left(a-t_{0}\right)}\right]^{3}
$$

where $W_{\infty}$ is the asymptotic weight, $k$ is the growth parameter and $t_{0}$ is the theoretical age-at-birth.

Recruit (fecundity) per spawning biomass $\left(m_{a}\right)$ was calculated using the following:

$$
m_{a}=\frac{B_{a} \cdot \rho_{a}}{a}
$$




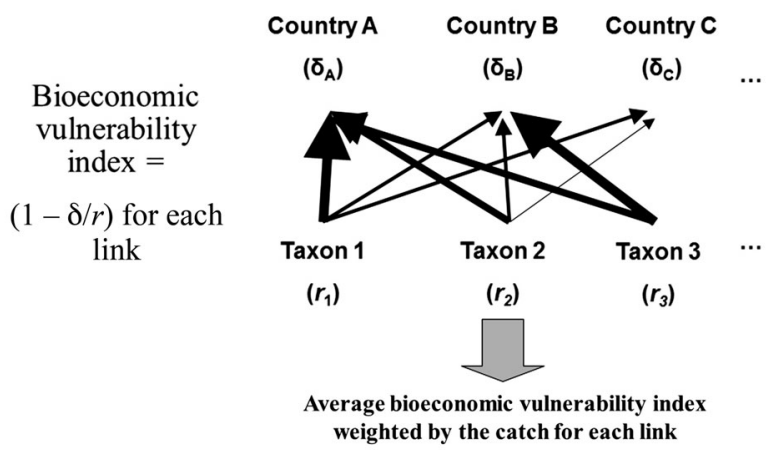

Fig. 1. Schematic summarizing the algorithm developed to calculate the bioeconomic vulnerability index in each $0.5^{\circ}$ latitude $\times 0.5^{\circ}$ longitude cell of the world ocean. Thickness of arrows represents the weight of a fish taxon $(1,2,3$, etc.) caught by a country (A, B, C etc.) with the respective discount rate $\delta\left(\delta_{\mathrm{A}}, \delta_{\mathrm{B}}, \delta_{\mathrm{C}}\right.$, etc. $)$ while $r\left(r_{1}, r_{2}, r_{3}\right.$, etc. $)$ is the estimated intrinsic rate of population increase of a fish population

Biological parameters were obtained from online databases. Life history parameters, including the von Bertalanffy growth parameters, age-at-maturity, longevity and natural mortality rates for all the 852 species were obtained from the FishBase database (www.fishbase.org). For higher taxonomic level taxa (genus and family levels), the average values of the species belonging to the same genus and family were used.

Since estimates for the steepness parameter $h$ are not available for most of the species, we used a range of values of $h$ reported in published studies (see Myers et al. 1999). A meta-analysis of over 700 stock-recruitment relationships allowed for the estimation of average steepness $h$ parameters for 57 fish species (Myers et al. 1999). These estimated $h$ parameters have a median of 0.62 and an upper $(75 \%)$ and lower $(25 \%)$ quartile of 0.82 and 0.48 , respectively. We calculated the mid-, upper- and lowerrange estimates of $r$ by applying the median upper and lower quartile values of the $h$ parameter to Eq. (13). This also provided the mid-, upperand lower-range estimates of the vulnerability index (Eq. 7).

Using the estimated intrinsic population growth rate $r$ (expressed as annual rate) and discount rate $\delta$, we calculated the vulnerability index for each taxon-fishing country combina- tion. We then calculated an average vulnerability index for all taxon-fishing country combinations weighted by their catch (Fig. 1). This was repeated for all the spatial cells using estimates of $r$ under the mid-, upper- and lower-range values.

\section{RESULTS}

Our results show that bioeconomic vulnerability was high in many regions. Regions with high vulnerability to overfishing are indicated by cells with a high negative bioeconomic vulnerability index value. Considering all the 852 fish taxa included in this study and assuming that fisheries operated with the official country-level discount rate, vulnerability to overfishing was predicted to be high in the following regions: northeastern coast of Canada, the Pacific coast of Mexico, Peruvian coast, South Pacific (offshore of New Zealand in particular), southern and southeastern coast of Africa, and the Antarctic region (Fig. 2A). Regions with the highest vulnerability include the central East Pacific, Southern Ocean and Antarctic region.

Vulnerability calculated based on estimates from country-level discount rates probably largely underestimated the potential vulnerability because
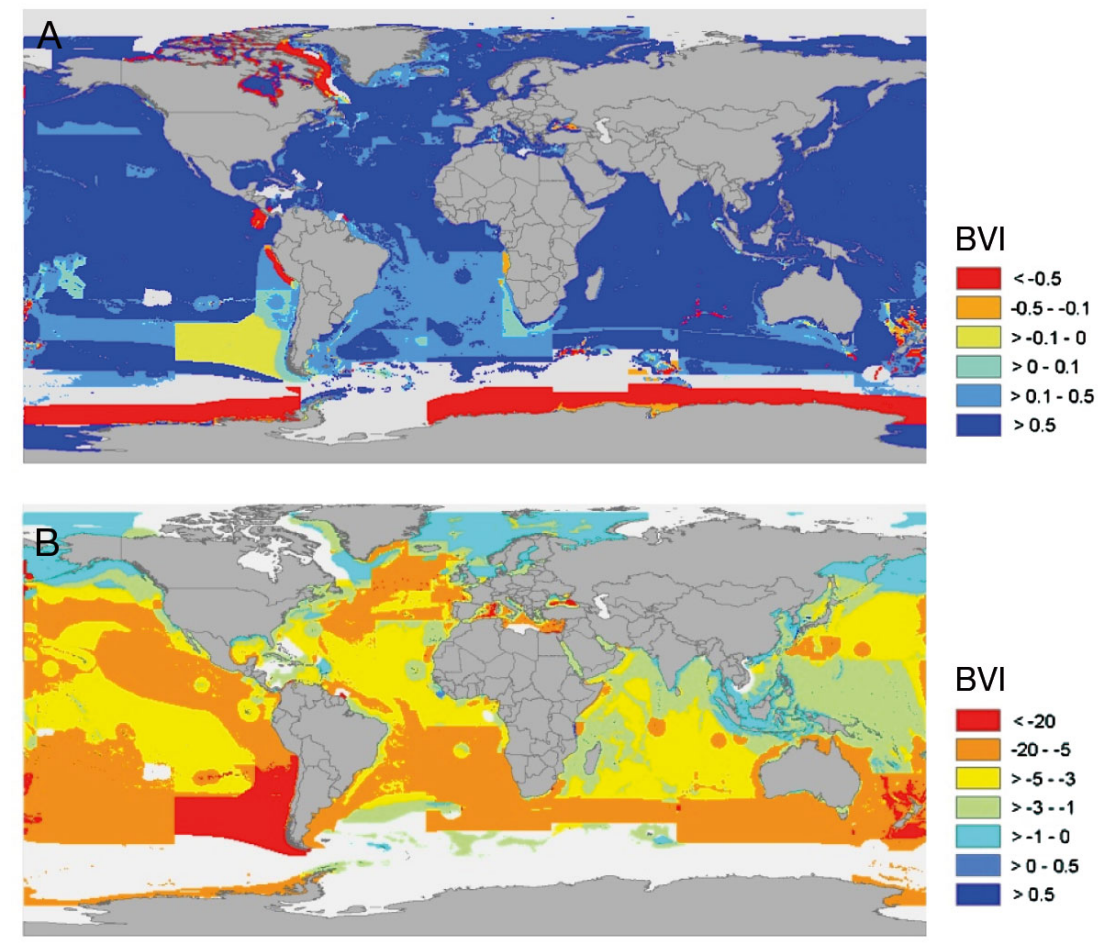

Fig. 2. Bioeconomic vulnerability index (BVI) of all exploited fishes calculated based on (A) country-level and (B) private discount rates 
of the difference between countrylevel and private-discount rates. When estimated private discount rates were used instead of countrylevel discount rates, most of the world ocean became highly vulnerable to overfishing (bioeconomic vulnerability index <0) (Fig. 2B). Particularly, regions with high vulnerability expanded into the Mediterranean Sea, mid-Atlantic, Arctic, west and south coast of Australia and the central Pacific.

When demersal and pelagic fishes were analyzed separately, different patterns of vulnerability to overfishing emerged (Fig. 3). Because of the high catch of pelagic fishes, the vulnerability index for all fishes weighted towards the pelagic groups (Fig. 3A,B). Thus, the general pattern of vulnerability of pelagic fishes is similar to that of all fishes, except in some areas in the Arctic and around the Antarctic where pelagic fishes were not reported. For demersal fishes, high vulnerability areas are concentrated in the continental shelf region (Fig. 3C,D). Vulnerability is particularly high offshore of the central eastern Pacific, southwest Atlantic, around Iceland, south of the Indian coast and the Indo-Pacific region.

The high vulnerability to overfishing in many regions is largely driven by high discount rates, while in some regions low intrinsic growth rates also contribute to it (Fig. 4). In most areas, the average intrinsic growth rate weighted by the catch of each taxon ranges from 0.1 to 0.5 . The Arctic (along the north coast of North America) and the Antarctic show high average intrinsic rates as a result of the low diversity of exploited fish with mostly slowgrowing life histories. Country-level
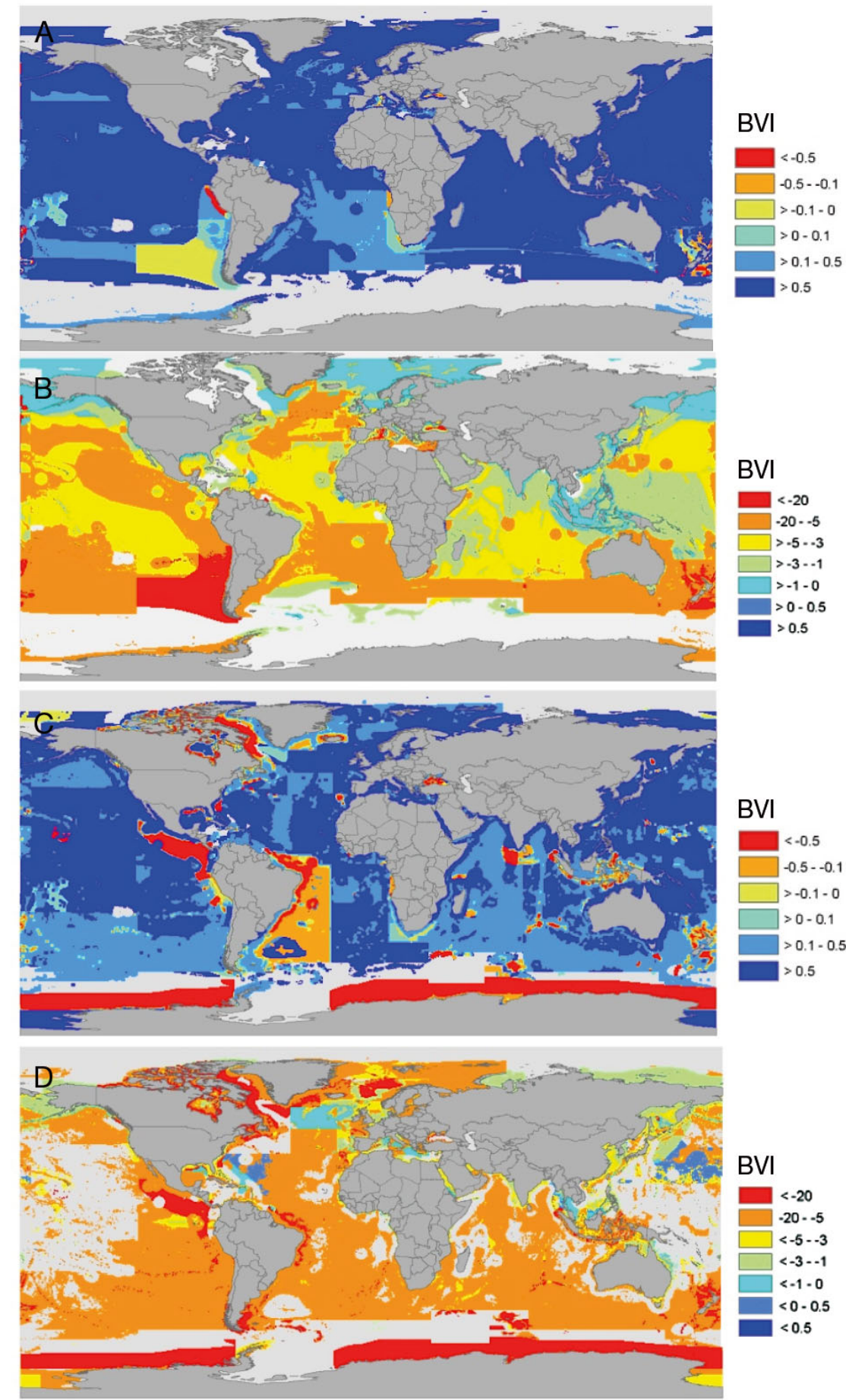

Fig. 3. Bioeconomic vulnerability index (BVI) for pelagic $(A, B)$ and demersal $(C, D)$ fishes calculated based on $(A, C)$ country-level and $(B, D)$ private discount rates

discount rates are highest in the southwest Atlantic, part of the central Atlantic and Pacific and the Indo-Pacific regions. Private discount rates are high in most of the world oceans, particularly the Canadian Arctic, the central and southeast Pacific, West African coast, the western Indian Ocean, and around New Zealand. In these regions, private discount rates were estimated to be over $180 \%$. 


\section{DISCUSSION}

The bioeconomic vulnerability index highlighted areas where the intrinsic risk of over-exploitation from fishing is relatively higher. Some areas identified as vulnerable coincide with regions that are identified as over-exploited or rebuilding from overfishing (Worm et al. 2009), including the northeastern coast of Canada and the Pacific coast of Mexico. However, the index does not consider the effectiveness of existing fisheries management measures. Thus, fisheries in areas with high bioeconomic vulnerability, such as the waters around New Zealand, may not be over-exploited because of effective management. On the other hand, areas with poor fisheries management effectiveness, such as in fisheries of some developing countries, could be more vulnerable to over-exploitation than areas in New Zealand waters. Moreover, the vulnerability of developing countries' regions may be under-estimated because of the lack of good-quality fisheries data.

Our results highlight the potentially tough trade-off in fisheries management in many parts of the world ocean. Such a trade-off is expected to be most intense in areas where vulnerability to overfishing is high; meaning that the economic incentive to over-exploit is strong for the fishing industry and the society, while productivity of fishes is low. In these areas, effective fisheries management is more urgently needed, if not already implemented, to help protect the vulnerable ecosystem. For example, if the main driver for the high discount rate at the country and private levels is poverty, alleviating poverty in these regions should be a priority (Brashares et al. 2014). In cases where a large part of the distribution range of low-productivity species falls within these regions, fishing may greatly increase the risk of overexploitation. Creating marine reserves, to protect such species, may become a necessary strategy to safeguard their continued existence.

A 'win-win' solution between conservation and economic gains is most likely in areas where bio-
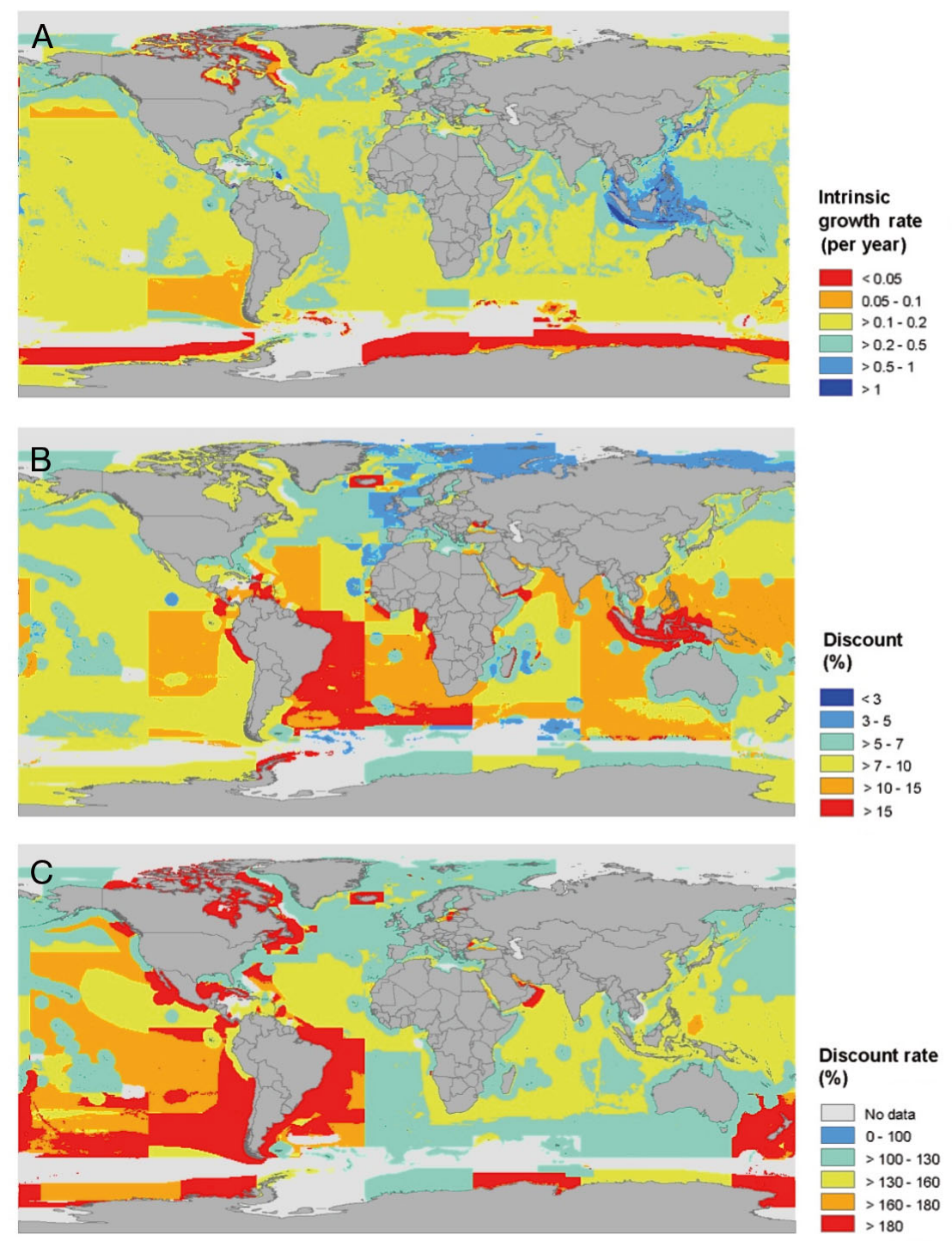

Fig. 4. Parameters that were used to calculate the bioeconomic vulnerability index: (A) average intrinsic growth rate of the exploited fishes, (B) countrylevel discount rate, and $(\mathrm{C})$ private discount rates of the fishing countries in each $0.5^{\circ} \times 0.5^{\circ}$ cell

economic vulnerability at both country and private levels is low, while the average intrinsic population growth rates of the exploited species are high. An example is the Gulf of Alaska. Since there is reasonable economic incentive for conservation, a range of fisheries management options is likely to be effective. It has been suggested that the effectiveness of different governance systems (e.g. command-andcontrol, privatization, exclusive fishing rights, allocated quotas, self-governance and co-management) in achieving sustainable fisheries management is dependent on the difference in discount rates between regulators (e.g. the state) and fishers (Sumaila \& Domínguez-Torreiro 2010). In this case, since the 
motivation to conserve by both the fishing sector and the regulator is likely to be high, management policies that involve self-governance or co-management could be effective.

Various uncertainties exist that may affect the interpretation of the bioeconomic vulnerability index at the global scale. Because our study is at a global scale, it does not represent detailed regional and local differences in the ecology and socio-economics of fisheries. For example, intrinsic population growth rate and discount rate can vary between different stocks (for a species), regions and time. In the future, regional applications of the index could better reflect complexity at finer spatial scales. On the other hand, fisheries and socio-economic data are largely limited in many regions, particularly in economically developing areas. The broad globalscale approach employed in this study allowed us to evaluate general patterns and highlight priority areas for further analysis. Empirically estimated discount rates for fishing countries and fishers are rarely available. Thus, we had to make assumptions in estimating the discount rates, which may not accurately reflect the true values. Specifically, we used the limited available estimates of private discount rate for fisheries, which are largely from developing countries and small-scale fisheries, and extrapolated these to developed regions and largescale fisheries albeit after using the Human Development Index to differentiate countries.

It is worth noting that the discount rates of developing countries and small-scale fisheries may be much higher than other fisheries in developed countries, and that the validity of the extrapolation of discount rates assumed in our study is uncertain. Thus, vulnerability of some of the fisheries may be over-estimated when the extrapolated private discount rates were used. Similarly, estimated intrinsic rates of population increase are considered an approximation, with one of the main uncertainties being the estimation of the steepness parameter $h$. Our analyses suggest that alternative estimates of discount rate and intrinsic rate of population increase affect the absolute values of the vulnerability index. However, the relative differences in vulnerability between regions are generally robust to alternative values of $\delta$ and $r$. The advantage of our approach is that the range of discount rates and intrinsic growth rates used in the analysis can easily be varied and the model re-run.

Calculated vulnerability may vary depending on the structure of the algorithm used in calculating the vulnerability index. For example, the vulnerability index does not incorporate the marginal stock effect
(Clark \& Munro 1975, Clark et al. 1979) or the effects of detrimental subsidies to fishing (Sumaila et al. 2010), which would affect the incentive to overfish. Moreover, populations may interact ecologically through trophic linkages or technically through, e.g. bycatch, and this may affect their vulnerability. These secondary effects of fishing are not captured in the index. On the other hand, there are trade-offs between having a simple index with known structural uncertainty and a complex index that increases data uncertainty. For example, the Ocean Health Index (Halpern et al. 2012) is a comprehensive index to evaluate ocean sustainability. However, it is data intensive, and so the uncertainty associated with the large number of input data may complicate its interpretation. We opt for the earlier option as the primary objective of this study is to broadly identify areas of the world ocean with high potential vulnerability to overfishing. The global focus of the analysis and the inclusion of a large number of exploited species favour the use of a simple index that is of policy relevance.

Future studies should examine other factors not explored in this analysis that may affect the vulnerability of the exploited populations. We did not include invertebrate fisheries in this study. Since invertebrates are generally more resilient to overfishing relative to fishes, this study may over-estimate the vulnerability of regions where invertebrates are an important part of the fishery. Further studies can apply the vulnerability index described here to the invertebrate fisheries. These would include the incorporation of the marginal stock effect and subsidies into the assessment of vulnerability and effectiveness of existing fishing management measures. Particularly, the established global databases on fish prices (Sumaila et al. 2007, Swartz et al. 2013), fishing cost (Lam et al. 2011), fishing effort (Anticamara et al. 2011) and subsidies (Sumaila et al. 2010) would facilitate such an analysis. Also, we propose that there is a need to carry out more studies on public and private (fishing sector) discount rates to improve our understanding of the economic drivers of overexploitation.

\section{CONCLUSIONS}

Using the bioeconomic vulnerability index developed in this paper, we show that some areas of the world ocean are likely to face difficult trade-offs between conservation and exploitation. Exploited fish populations in these regions have relatively low 
intrinsic biological vulnerability to fishing (low intrinsic rate of population increase) while the economic incentive to over-exploit, driven by high discount rates, is strong. In contrast, areas with low vulnerability suggest that conservation and fishing exploitation could coexist without much conflict of interest. Future incorporation of the marginal stock effects, subsidies, improved biological and economic data could refine the general picture depicted in this study. Studies that incorporate an analysis of how existing management arrangements are likely to affect the patterns identified in the current contribution would be very interesting.

Acknowledgements. This project is funded by the Pew Charitable Trust through U.R.S.'s Pew Marine Conservation fellowship. W.W.L.C. acknowledges funding support from the National Geographic Society, Natural Sciences and Engineering Research Council of Canada, and Nippon Foundation. We thank M. L. D. Palomares for provision of data from FishBase.

\section{LITERATURE CITED}

Akpalu W (2008) Fishing regulations, individual discount rate, and fisherman behaviour in a developing country fishery. Environ Dev Econ 13:591-606

> Anticamara JA, Watson R, Gelchu A, Pauly D (2011) Global fishing effort (1950-2010): trends, gaps, and implications. Fish Res 107:131-136

Arnason R, Kelleher K, Willmann R (2009) The sunken billions: the economic justification for fisheries reform. The World Bank, Washington, DC and FAO, Rome

Brashares JS, Abrahms B, Fiorella KJ, Golden CD and others (2014) Wildlife decline and social conflict. Science 345: 376-378

> Cheung WWL, Pitcher TJ (2008) Evaluating the status of exploited taxa in the northern South China Sea using intrinsic vulnerability and spatially explicit catch-perunit-effort data. Fish Res 92:28-40

> Cheung WWL, Pitcher TJ, Pauly D (2005) A fuzzy logic expert system to estimate intrinsic extinction vulnerabilities of marine fishes to fishing. Biol Conserv 124:97-111

Cheung WWL, Watson R, Morato T, Pitcher TJ, Pauly D (2007) Intrinsic vulnerability in the global fish catch. Mar Ecol Prog Ser 333:1-12

Clark CW (1973) The economics of overexploitation. Science 181:630-634

Clark CW, Munro GR (1975) The economics of fishing and modern capital theory: a simplified approach. J Environ Econ Manag 2:92-106

Clark CW, Clarke FH, Gordon RM (1979) The optimal exploitation of renewable resource stocks: problems of irreversible investment. Econometrica 47:25-47

> Doroff AM, Estes JA, Tinker MT, Burn DM, Evans TJ (2003) Sea otter population declines in the Aleutian Archipelago. J Mammal 84:55-64

> Dulvy NK, Sadovy Y, Reynolds JD (2003) Extinction vulnerability in marine populations. Fish Fish 4:25-64

> Dyck A, Sumaila U (2010) Economic impact of ocean fish populations in the global fishery. J Bioeconomics 12: $227-243$

FAO (Food and Agriculture Organization of the United Nations)(2011) The state of world fisheries and aquaculture 2010. FAO, Rome

Fehr E, Leibbrandt A (2008) Cooperativeness and impatience in the tragedy of the commons. IZA Discuss Pap No. 3625. Institute for the Study of Labor, Bonn

Halpern BS, Longo C, Hardy D, McLeod KL and others (2012) An index to assess the health and benefits of the global ocean. Nature 488:615-620

Lam VWY, Sumaila UR, Dyck A, Pauly D, Watson R (2011) Construction and first applications of a global cost of fishing database. ICES J Mar Sci 68:1996-2004

> Mangel M, Brodziak J, DiNardo G (2010) Reproductive ecology and scientific inference of steepness: a fundamental metric of population dynamics and strategic fisheries management. Fish Fish 11:89-104

McAllister MK, Pikitch EK, Babcock EA (2001) Using demographic methods to construct Bayesian priors for the intrinsic rate of increase in the Schaefer model and implications for stock rebuilding. Can J Fish Aquat Sci 58: 1871-1890

Myers RA, Bowen KG, Barrowman NJ (1999) Maximum reproductive rate of fish at low population sizes. Can J Fish Aquat Sci 56:2404-2419

> Norse EA, Brooke S, Cheung WWL, Clark MR and others (2012) Sustainability of deep-sea fisheries. Mar Policy 36: 307-320

Pitcher TJ, Lam ME (2010) Fishful thinking: rhetoric, reality, and the sea before us. Ecol Soc 15:12. www.ecologyand society.org/vol15/iss12/art12/

Reynolds JD, Dulvy NK, Goodwin NB, Hutchings JA (2005) Biology of extinction risk in marine fishes. Proc R Soc Lond B Biol Sci 272:2337-2344

Roy N, Arnason R, Schrank WE (2009) The identification of economic base industries, with an application to the Newfoundland fishing industry. Land Econ 85:675-691

Sadovy Y, Cheung WL (2003) Near extinction of a highly fecund fish: the one that nearly got away. Fish Fish 4:86-99

Sadovy de Mitcheson Y, Craig MT, Bertoncini AA, Carpenter KE and others (2013) Fishing groupers towards extinction: a global assessment of threats and extinction risk in a billion dollar fishery. Fish Fish 14:119-136

> Sumaila UR (2004) Intergenerational cost-benefit analysis and marine ecosystem restoration. Fish Fish 5:329-343

Sumaila UR, Domínguez-Torreiro M (2010) Discount factors and the performance of alternative fisheries governance systems. Fish Fish 11:278-287

Sumaila UR, Walters C (2005) Intergenerational discounting: a new intuitive approach. Ecol Econ 52:135-142

Sumaila U, Marsden A, Watson R, Pauly D (2007) A global ex-vessel fish price database: construction and applications. J Bioeconomics 9:39-51

Sumaila U, Khan A, Dyck A, Watson R, Munro G, Tydemers P, Pauly D (2010) A bottom-up re-estimation of global fisheries subsidies. J Bioeconomics 12:201-225

Swartz W, Sumaila R, Watson R (2013) Global ex-vessel fish price database revisited: a new approach for estimating 'missing' prices. Environ Resour Econ 56:467-480

Teh LSL (2011) Discount rates, small-scale fisheries, and sustainability. PhD thesis, University of British Columbia, Vancouver

Teh LC, Teh LS, Starkhouse B, Rashid Sumaila U (2009) An overview of socio-economic and ecological perspectives 
of Fiji's inshore reef fisheries. Mar Policy 33:807-817

Teh LS, Teh LC, Sumaila UR (2011) Quantifying the overlooked socio-economic contribution of small-scale fisheries in Sabah, Malaysia. Fish Res 110:450-458

Teh LS, Teh LC, Rashid Sumaila U (2014) Time preference of small-scale fishers in open access and traditionally managed reef fisheries. Mar Policy 44:222-231

Submitted: March 17, 2014; Accepted: November 24, 2014
Walters CJ, Martell SJ (2004) Fisheries ecology and management. Princeton University Press, Princeton, NJ

> Watson R, Kitchingman A, Gelchu A, Pauly D (2004) Mapping global fisheries: sharpening our focus. Fish Fish 5: 168-177

Worm B, Hilborn R, Baum JK, Branch TA and others (2009) Rebuilding global fisheries. Science 325:578-585

Proofs received from author(s): March 8, 2015 